\section{Impact of Hydraulic Characteristics of Raw or Composted Posidonia Residues, Coir, and Their Mixtures with Pumice on Root Aeration, Water Availability, and Yield in a Lettuce Crop}

George Gizas, Ioannis Tsirogiannis, Maria Bakea, and Nikolaos Mantzos Faculty of Agricultural Technology, TEI of Epirus, P.O. Box 110, 47100, Arta, Greece

\section{Dimitrios Savvas ${ }^{1}$ \\ Laboratory of Vegetable Crops, Agricultural University of Athens, Iera Odos 75, 11855 Athens, Greece}

Additional index words. coconut, compost, growing media, hydraulic conductivity, Lactuca sativa, soilless culture, water retention curve

\begin{abstract}
The residues of the aquatic plant Posidonia oceanica that are washed ashore, thereby causing environmental problems in coastal areas, can be used as growing media in horticulture. In the present study, the hydraulic characteristics of raw or composted Posidonia residues, coir, and their $1: 1$ blends (v/v) with pumice were determined, and their agronomic performance was evaluated in a lettuce crop. The mixture of all three substrates with pumice reduced their effective pore space and increased their bulk density. Furthermore, the water and air capacity (determined at a suction of $10 \mathrm{~cm}$ ) and the easily available water were also reduced by mixing the three tested media with pumice. The relative hydraulic conductivity $\left(K_{r}\right)$ decreased with increasing suction $(\psi)$ in all of the tested media. The highest and the lowest rates of $K_{r}$ decrease with increasing $\psi$ were observed in the mix of non-composted Posidonia with pumice and in $100 \%$ composted Posidonia, respectively. Blending composted or non-composted Posidonia with pumice at a 1:1 ratio raised the rate of $K_{r}$ decrease with increasing $\psi$ in comparison with $100 \%$ composted or $100 \%$ non-composted Posidonia, respectively. In contrast, blending coir with pumice reduced the rate of $K_{r}$ decrease with increasing $\psi$ in comparison with $100 \%$ coir. The differences in the mean fresh weight between lettuce plants grown on the six growing media were similar with those in the rate of $K_{r}$ decrease with increasing $\psi$. These results indicate that the crucial factor for the yield performance of lettuce grown on the tested growing media was not the air but the water availability. Furthermore, the present results indicate that the actual water availability to plants grown on the tested substrates depends much more on water flux toward roots and concomitantly on their hydraulic conductivity than on the easily available water (i.e., the difference in water content between 10 and $50 \mathrm{~cm}$ suction).
\end{abstract}

The cultivation of greenhouse plants on substrates is considered an efficient alternative to soil sterilization, especially in view of the phase-out of methyl bromide in compliance to the Montreal protocol resulting from its adverse effects on the environment. Moreover, the cultivation of greenhouse crops on substrates is possible even in saline, sodic, or infertile soils with poor structure, which represent a major proportion of arable land throughout the world (Bougoul et al., 2005; Savvas,

Received for publication 27 Dec. 2011. Accepted for publication 8 Mar. 2012.

This research was supported by an INTERREG IIIA GREECE-ITALY research project entitled "Posidonia oceanica: Protection and regeneration of fields and use of residuals in agriculture (POPRURA)" (I3101017, Category: D2).

${ }^{1}$ To whom reprint requests should be addressed; e-maildsavvas@aua.gr. potamogetonaceae of the Monocotyledoneae class, is very common in the Mediterranean Sea and is deposited annually on the coasts. These deposits cause serious environmental and aesthetical problems to the beaches in all Mediterranean countries (Cocozza et al., 2011). The need to dispose of the Posidonia residues washed ashore has led researchers to test the possibility of composting this material to use it as a horticultural substrate in place of peat (Castaldi and Melis, 2004). Recently, some attempts have been made to use Posidonia deposits as growing media in soilless culture (Serio et al., 2004). However, to successfully use a new porous material as a horticultural substrate, it is important to know its physical and hydraulic properties and test them under real growing conditions. Furthermore, the commercial availability of a new substrate requires proper package and standardization. Up to date, such information is not available in the international scientific literature and this makes it urgently necessary to conduct comprehensive research in this area. The most important questions that should be addressed regarding the use of Posidonia as a horticultural substrate include the form in which this material should be used (composted or raw after chopping in small pieces), the hydraulic properties, and the geometry of the bag or container used as substrate receptor.

Water retention curves described by model equations may enable an accurate estimation of the actual air and water content of a containerized substrate at container capacity when the height of the latter in the container is given (Al Naddaf et al., 2011). Furthermore, such model equations can be used to estimate the changes in the unsaturated hydraulic conductivity as the height of the substrate increases (Al Naddaf et al., 2011; Raviv et al., 1999). Hence, when the moisture characteristic of a substrate is described by a known model equation, the latter can be used to optimize the geometry of the bags used to standardize and pack this substrate.

As a rule, root aeration in organic media seems to be improved when they are mixed with coarse inorganic materials (Spomer, 1974). However, mixing different media may alter not only the air capacity in the obtained blend, but also the unsaturated hydraulic conductivity, which is crucial for the water availability to the plants grown on them (Wallach, 2008). Up to date, there are only few reports in the international scientific literature that are concerned with the effect of mixing different substrates on hydraulic conductivity (Papadopoulos et al., 2008). Because blending two or more different substrates may modify also the effective pore space and the mean pore size (Burés et al., 1993), an improvement in water availability is not necessarily accompanied by restrictions in root aeration and vice versa. Nevertheless, the impact of mixing different substrates depends predominantly on the specific combination. With respect to Posidonia, up to date there are no reports as to whether mixing this organic residue with inorganic porous materials improves the physical properties 
and the agronomic performance of the obtained blend.

As a contribution to the use of Posidonia residues in horticulture, the present research was aimed at determining the physical and hydraulic properties and assessing the agronomic performance of raw shredded Posidonia residues as well as composted Posidonia residues when used either unmixed or mixed with inorganic media. The inorganic substrate that was mixed with Posidonia residues in the present study is pumice, a natural porous aggregate that is characterized by a low carbon footprint, because it is not subjected to any thermal treatment before use. The physical properties of pumice have been determined in a previous study (Gizas and Savvas, 2007) and thus it is possible to compare the blends of Posidonia and pumice not only with one, but with both of their constituents. To obtain an overall assessment of the prospects of using Posidonia residues as growing media in horticulture, coir, which is a standard organic substrate (Evans et al., 1996; Maher et al., 2008), was also included in the present research either unmixed or mixed with pumice.

\section{Materials and Methods}

Substrate treatments. The horticultural substrates tested in this study were coir, noncomposted Posidonia, composted Posidonia, and their mixes (1:1) with 0 to $8 \mathrm{~mm}$ pumice. The Posidonia residues used as noncomposted growing medium were selected from the coastline of Preveza and subjected to careful washing to remove salts and chopping into small pieces of $\approx 4 \mathrm{~mm}$ or less before use. The composted Posidonia was purchased from Compost Hellas A.E. The evaluation included determination of physical characteristics, chemical properties (not presented in this article), and agronomic performance in a soilless cultivation of lettuce.

Determination of the physical and hydraulic characteristics of the substrates. The water retention curves (WRC) of coir, non-composted Posidonia, composted Posidonia, and their mixes (1:1) with pumice were determined using a sandbox apparatus (Eijkelkamp, The Netherlands). The samples of substrate were placed in $100-\mathrm{cm}^{3}$ rings with their bottoms covered by a piece of ultrathin capillary material supplied by the manufacturer, which aimed to prevent loss of sample when the rings were removed for weighing. Each of the five tested substrates was replicated four times. Initially, the samples were saturated with distilled water by setting them in $1 \mathrm{~cm}$ water in the sandbox, waiting for $1 \mathrm{~h}$, and then slowly raising the water level to the top of the ring for a period of $5 \mathrm{~d}$. After establishment of saturation, the samples were subjected to a water suction of $100 \mathrm{~cm}$ $(10 \mathrm{kPa})$ to precisely tune their volume to $100 \mathrm{~cm}^{3}$ and then resaturated with water like in the initial saturation process. Subsequently, their moisture content was gradually decreased by exposing them to increasing suction regimes up to a level of $100 \mathrm{~cm}$. To ensure establishment of steady moisture conditions in the bulk of the samples at each suction level, the time intervals between each step of suction increase were at least $5 \mathrm{~d}$. After establishment of moisture equilibrium at each suction level, the samples were removed from the sandbox by means of a sharp slice, weighed, and then returned back to their position. Finally, all samples were oven-dried and weighed to determine their dry weight. Thus, the actual moisture content $(\theta)$ was estimated by deducting the dry weight from the actual weight of the sample at each suction regime. The bulk density (BD) was estimated as sample dry weight-to-volume ratio $\left(\mathrm{g} \cdot \mathrm{cm}^{-3}\right)$. The WRC of the six tested substrates were graphically depicted by presenting both the means of the four measured values of $\theta$ at each suction level and the corresponding best fit curves. The latter were established by using a model proposed by Van Genuchten (1980) and Van Genuchten and Nielsen (1985) for soils and adapted to horticultural substrates by Milks et al. (1989):

$$
S_{e}=\left[1+(a h)^{n}\right]^{-m}
$$

where $h$ is the water suction in $\mathrm{cm}$ of water, $a$ and $n$ are parameters depending on the physical characteristics of the substrate, which were determined empirically by nonlinear regression analysis, $m=1-1 / n$, and $S_{e}$ is the effective saturation, which, by definition (Da Silva et al., 1993), is given by equation:

$$
S_{e}=\left(\theta-\theta_{r}\right) /\left(\theta_{s}-\theta_{r}\right)
$$

In Eq. (2), $\theta$ depicts the volumetric moisture content of the substrate and the subscripts $s$ and $r$ refer to the saturated and residual moisture content, respectively. Substituting (2) in (1) renders:

$$
\theta=\theta_{r}+\left(\theta_{s}-\theta_{r}\right) /\left[1+(a h)^{n}\right]^{m}
$$

As previously mentioned, $\theta_{s}$ was measured, whereas $\theta_{r}$ was estimated by nonlinear regression analysis to fit the measured data, as suggested by Raviv et al. (1999). Eq. (3) was further used to calculate the volumetric water content at container capacity, as defined by Bilderback and Fonteno (1987), for each of the tested media when placed in rectangular bags of different heights. This was attained by integrating (3) within the range from 0 to a certain bag height and dividing by the bag height (Gizas and Savvas, 2007; Savvas, 2009). In the present article, the volumetric water content of containerized substrates at container capacity is termed actual container capacity (ACC). In addition, the air content in each substrate at container capacity, henceforth termed actual air capacity (AAC), was also calculated for different bag heights by subtracting the corresponding water content at container capacity from the water content at saturation.

Based on the WRC, the following hydraulic properties were estimated for each of the tested substrates: 1) effective pore space (EPS: volumetric percentage of pore space that can be actually filled with water, corresponding to $\left.\theta_{s}\right) ; 2$ ) volumetric water content at $10 \mathrm{~cm}$ water suction, henceforth termed water capacity
(WC); 3) volumetric air content at $10 \mathrm{~cm}$ water suction, henceforth termed air capacity (AC); 4) easily available water (EAW: difference in volumetric water content between 10 and $50 \mathrm{~cm}$ water suction); and 5) water buffering capacity (WBC: difference in volumetric water content between 50 and $100 \mathrm{~cm}$ water suction). The definitions for these physical characteristics are those referenced by Bunt (1988).

The relative hydraulic conductivity of the tested media, $K_{r}$, which is defined as the ratio between the actual hydraulic conductivity, $K$, at a given suction, $h$, and the saturated hydraulic conductivity, $K_{s}$, was estimated using the van Genuchten-Mualem predictive model (Mualem, 1976; Van Genuchten, 1980):

$$
K_{r}=\frac{\left[1-(a h)^{n-1}\left(1+(a h)^{n}\right)^{-m}\right]^{2}}{\left(1+(a h)^{n}\right)^{m / 2}}
$$

Eq. (4), which is derived from Eq. (1) when assuming $m=1-1 / n$, enables a satisfactorily accurate prediction of the RHC in horticultural substrates, as has been shown by Wallach et al. (1992a, 1992b) for tuff, composted agricultural wastes and their mixes, Da Silva et al. (1993) for peat and its mixes with tuff, Heiskanen (1995) for sphagnum peatmoss mixes with coarse perlite, Raviv et al. (1999) for pumice, and Londra (2010) for peat, perlite, and mixtures of them.

Testing agronomic performance of the media. The agronomic performance of the six referenced media was evaluated in a greenhouse experiment using lettuce (Lactuca sativa L., cv. Great Lakes) as the test plant. The experiment was conducted in a heated glasshouse located in Arta (lat. 39 $7^{\prime} \mathrm{N}$, long. $20^{\circ} 56^{\prime}$ E) near the northwestern coast of Greece. The six tested growing media were placed into troughs with a length of $5 \mathrm{~m}$, a width of $10 \mathrm{~cm}$, and a height of $18 \mathrm{~cm}$. Each trough accommodated 25 lettuce plants and thus the volume of substrate per plant was 3.6 L. Each growing medium was replicated four times and thus there were 24 experimental units.

The troughs were perforated at their bottom with holes spaced every $20 \mathrm{~cm}$ and placed with a slope of $0.75 \%$ to allow for drainage of the surplus nutrient solution after each irrigation event. Polyethylene sheets placed beneath the troughs served to catch the drainage solution and collect it into a tank, which was placed at their lower end. After automatic registration of its volume, the drainage solution was discharged to avoid complications in the interpretation of the results. Before transplanting, the substrates in the troughs were soaked using a starter nutrient solution with an electrical conductivity (EC) of $2.6 \mathrm{dS} \cdot \mathrm{m}^{-1}$, a $\mathrm{pH}$ of 5.6 , and nutrient concentrations corresponding to standard recommendations for the root environment in lettuce crops (Sonneveld and Straver, 1994). During the cropping period, a standard nutrient solution for lettuce was supplied to the plants with an EC of $2.3 \mathrm{dS} \cdot \mathrm{m}^{-1}$ and a composition (Table 1) aimed at maintaining the nutrient concentrations in the root zone close to those in the starter solution. 
The lettuce seedlings were transplanted at the stage of four true leaves on 28 Dec. 2008. After establishment of the crop, the seedlings were supplied regularly with nutrient solution

Table 1. Composition of the nutrient solution supplied to all lettuce treatments during the experiment.

\begin{tabular}{lclc}
\hline Macronutrient & $\mathrm{mM}$ & Micronutrient & $\mu \mathrm{M}$ \\
\hline Potassium & 6.50 & Iron & 17 \\
Calcium & 4.80 & Manganese & 5 \\
Magnesium & 1.50 & Zinc & 5 \\
$\mathrm{NH}_{4}{ }^{-}$ & 1.00 & Copper & 0.8 \\
$\mathrm{NO}_{3}{ }^{-}$ & 14.60 & Boron & 25 \\
$\mathrm{SO}_{4}{ }^{-}$ & 2.00 & Molybdenum & 0.50 \\
Phosphorus $^{-}$ & 1.60 & & \\
\hline
\end{tabular}
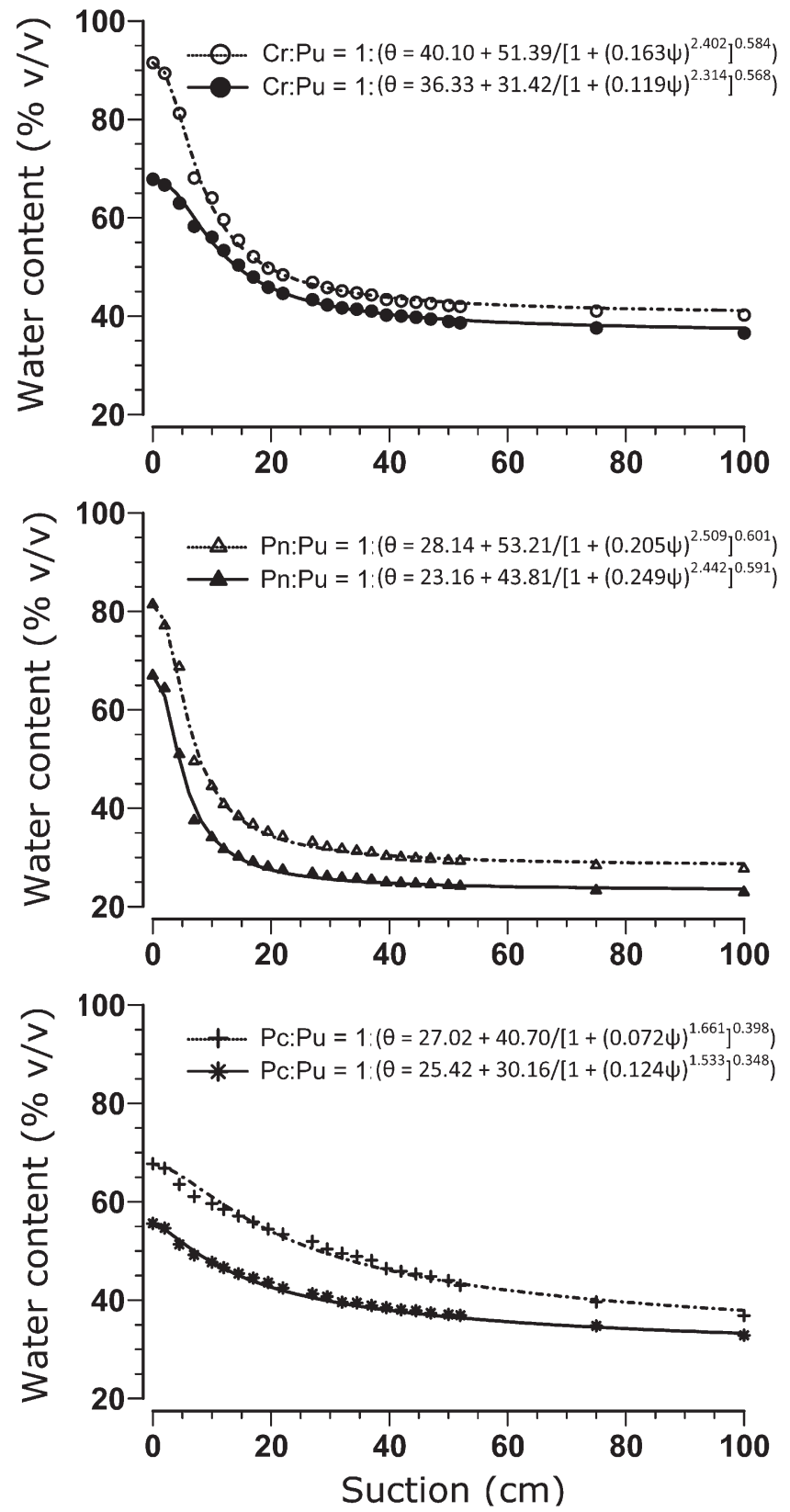

Fig. 1. Water retention curves of coir (Cr), non-composted Posidonia ( $\mathrm{Pn})$, composted Posidonia (Pc), and their mixtures $(1: 1)$ with pumice $(\mathrm{Pu})$. Symbols indicate means of four measured values, whereas curves were fitted by applying nonlinear regression analysis using Eq. (3) as a model. treatments ranged from $19 \%$ to $28.5 \%$ during the whole cropping period. This schedule resulted in three to six irrigation applications per day to each experimental unit depending on the prevailing weather conditions.

On 15 Feb. 2009, when the crop reached commercial maturity, all the plants from each experimental unit were harvested, and their weight was used to calculate a mean shoot fresh weight. Thus, four values of shoot fresh weight per treatment were used for statistical evaluation. Subsequently, the shoot of two plants randomly selected from each channel was dried at $70{ }^{\circ} \mathrm{C}$ to constant weight and the dried mass was weighed and subjected to chemical analysis as described in detail in a previous paper (Savvas et al., 2006) to determine their nutrient status (nitrogen, phosphorus, potassium, calcium, magnesium, iron, manganese, zinc, copper, and boron). The two measurements per channel were used to calculate a mean value per experimental unit. Thus, four replications were available for each treatment. The data were evaluated by analysis of variance and the means were separated by applying the Duncan's multiple range test at $P=0.05$ using the PlotIT3.2 work package.

\section{Results}

The WRC of the three tested substrates (coir, raw Posidonia residues, and composted Posidonia residues) and their 1:1 mixes with pumice are shown in Figure 1. In addition to the measured values, the curves fitted by means of nonlinear regression analysis using Eq. (3) are also shown. Overall, the measured values were in good agreement with the curves simulated using the model of Van Genuchten (1980). Mixing coir and unprocessed or composted Posidonia residues with pumice altered considerably their WRC, especially in the initial part of the curves, namely in suctions ranging from 0 to $50 \mathrm{~cm}$. The bulk density of both coir and Posidonia increases considerably when these materials are mixed with pumice but the difference between composted Posidonia alone and its 1:1 mix with pumice is low (Table 2). When considering the physical and hydraulic properties derived from the WRC, it becomes evident that mixing coir or Posidonia residues with pumice decreases the EPS, the WC (water content at a suction of $10 \mathrm{~cm}$ ), the AC (difference in the water content between 0 and $10 \mathrm{~cm}$ suction), and the EAW (difference in water content between 10 and $50 \mathrm{~cm}$ suction). The largest differences are observed between coir and its 1:1 blend with pumice, whereas the smallest differences occur between composted Posidonia and its 1:1 blend with pumice. The WBC (difference in water content between 50 and $100 \mathrm{~cm}$ suction) tends also to decrease when the three tested media are mixed with pumice, but the difference is significant only between $100 \%$ composted Posidonia and its 1:1 mix with pumice.

The ACC, as estimated by integrating the equations simulating the WRC, tended to decrease in all of the tested substrates with 
increasing height of the substrate in the container (Fig. 2). The rate of decrease with increasing height was relatively high in sole coir and non-composted Posidonia both alone and in 1:1 blend with pumice, whereas it was low in a 1:1 blend of coir with pumice and in composted Posidonia both alone and blended with pumice. Sole coir exhibits the highest ACC when compared with the other media tested in this research, regardless of the media height in the container within the range from 4 to $20 \mathrm{~cm}$. On the other hand, the 1:1 mix of composted Posidonia with pumice exhibits the lowest ACC when the media height in the containers does not exceed $8 \mathrm{~cm}$. However, when the comparison is made for media heights exceeding $8 \mathrm{~cm}$ in the containers, the mix of non-composted Posidonia with pumice exhibits the lowest ACC. The mixture of the three tested substrates with pumice restricted appreciably the ACC of all media regardless of the substrate height. The AAC is very low (lower than $6 \%$ ) when the height of the substrate in the container is $4 \mathrm{~cm}$, but there are large differences between the three tested substrates and their 1:1 blends with pumice. The blend of coir and pumice and the composted Posidonia, both alone and mixed with pumice, exhibit very low AAC at $4 \mathrm{~cm}$, which do not exceed $1 \%(0.89 \%$, $0.73 \%$, and $1.25 \%$, respectively), whereas the blend of non-composted Posidonia with pumice exhibits the highest AAC (5.26\%). Furthermore, the rate of AAC increase with increasing height is very low in the three substrates with lower AAC than $1 \%$ at $4 \mathrm{~cm}$ height, whereas it is appreciably higher in coir alone and in non-composted Posidonia alone or in a mixture with pumice.

As indicated by the relationships between the $K_{r}$ and the suction, the hydraulic conductivity decreases sharply as the suction increases in all of the tested media (Fig. 3). The steepest decrease in $K_{r}$ as the suction increases is observed in non-composted Posidonia, whereas the lowest rate of $K_{r}$ decrease was found in composted Posidonia. When composted or non-composted Posidonia is mixed with pumice, the decrease in $K_{r}$ with increasing suction is slightly steeper in comparison with $100 \%$ composted or noncomposted Posidonia, respectively. The rate of $K_{r}$ decrease in coir as the suction increases is intermediate to those of composted and noncomposted Posidonia residues. However, in contrast to Posidonia, coir seems to benefit from mixing with pumice in terms of hydraulic conductivity, as indicated by the lower rate of $K_{r}$ decrease in the 1:1 blend in comparison with coir alone as the suction increases.

The highest mean fresh weight per lettuce plant was obtained from the mixtures of coir and composted Posidonia with pumice (Fig. 4). The mean fresh weight of plants grown on $100 \%$ composted Posidonia was slightly lower than that of the plants grown on the 1:1 blends of coir or composted Posidonia with pumice, but the differences were insignificant. In contrast, the plants grown on $100 \%$ coir exhibited a small but significant decrease in their mean fresh weight in
Table 2. Bulk density (BD), effective pore space (EPS), water capacity (WC; water content at a suction of $10 \mathrm{~cm}$ ), air capacity (AC; water content difference between 0 and $10 \mathrm{~cm}$ suction), easily available water (EAW; water content difference between 10 and $50 \mathrm{~cm}$ suction), and water buffering capacity (WBC; water content difference between 50 and $100 \mathrm{~cm}$ suction) of coir $(\mathrm{Cr})$, shredded Posidonia residues $(\mathrm{Pn})$, composted Posidonia residues $(\mathrm{Pc})$, and mixtures of them with pumice $(\mathrm{Pu})^{\mathrm{z}}$

\begin{tabular}{lcccccc}
\hline Substrate & BD $\left(\mathrm{g} \cdot \mathrm{cm}^{-3}\right)$ & EPS $(\% \mathrm{v} / \mathrm{v})$ & WC $(\% \mathrm{v} / \mathrm{v})$ & AC $(\% \mathrm{v} / \mathrm{v})$ & EAW $(\% \mathrm{v} / \mathrm{v})$ & WBC $(\% \mathrm{v} / \mathrm{v})$ \\
\hline $\mathrm{Cr}: \mathrm{Pu}=1: 0$ & $0.051 \mathrm{f}$ & $91.5 \mathrm{a}$ & $64.0 \mathrm{a}$ & $27.5 \mathrm{c}$ & $21.9 \mathrm{a}$ & $3.80 \mathrm{c}$ \\
$\mathrm{Cr}: \mathrm{Pu}=1: 1$ & $0.502 \mathrm{c}$ & $67.8 \mathrm{c}$ & $56.0 \mathrm{c}$ & $11.8 \mathrm{~d}$ & $17.1 \mathrm{~b}$ & $3.44 \mathrm{c}$ \\
$\mathrm{Pn}: \mathrm{Pu}=1: 0$ & $0.093 \mathrm{e}$ & $81.4 \mathrm{~b}$ & $44.5 \mathrm{e}$ & $36.9 \mathrm{a}$ & $15.1 \mathrm{~b}$ & $1.71 \mathrm{~d}$ \\
$\mathrm{Pn}: \mathrm{Pu}=1: 1$ & $0.379 \mathrm{~d}$ & $67.0 \mathrm{c}$ & $34.1 \mathrm{f}$ & $32.9 \mathrm{~b}$ & $9.7 \mathrm{c}$ & $1.43 \mathrm{~d}$ \\
$\mathrm{Pc}: \mathrm{Pu}=1: 0$ & $0.715 \mathrm{~b}$ & $67.7 \mathrm{c}$ & $59.6 \mathrm{~b}$ & $8.1 \mathrm{e}$ & $15.6 \mathrm{~b}$ & $9.47 \mathrm{a}$ \\
$\mathrm{Pc}: \mathrm{Pu}=1: 1$ & $0.812 \mathrm{a}$ & $55.6 \mathrm{~d}$ & $47.7 \mathrm{~d}$ & $7.9 \mathrm{e}$ & $9.7 \mathrm{c}$ & $5.18 \mathrm{~b}$ \\
\hline
\end{tabular}

${ }^{2}$ Values are means of four measurements. In each column, values followed by the same letter do not differ significantly at $P \leq 0.05$ according to the Duncan's multiple range test.
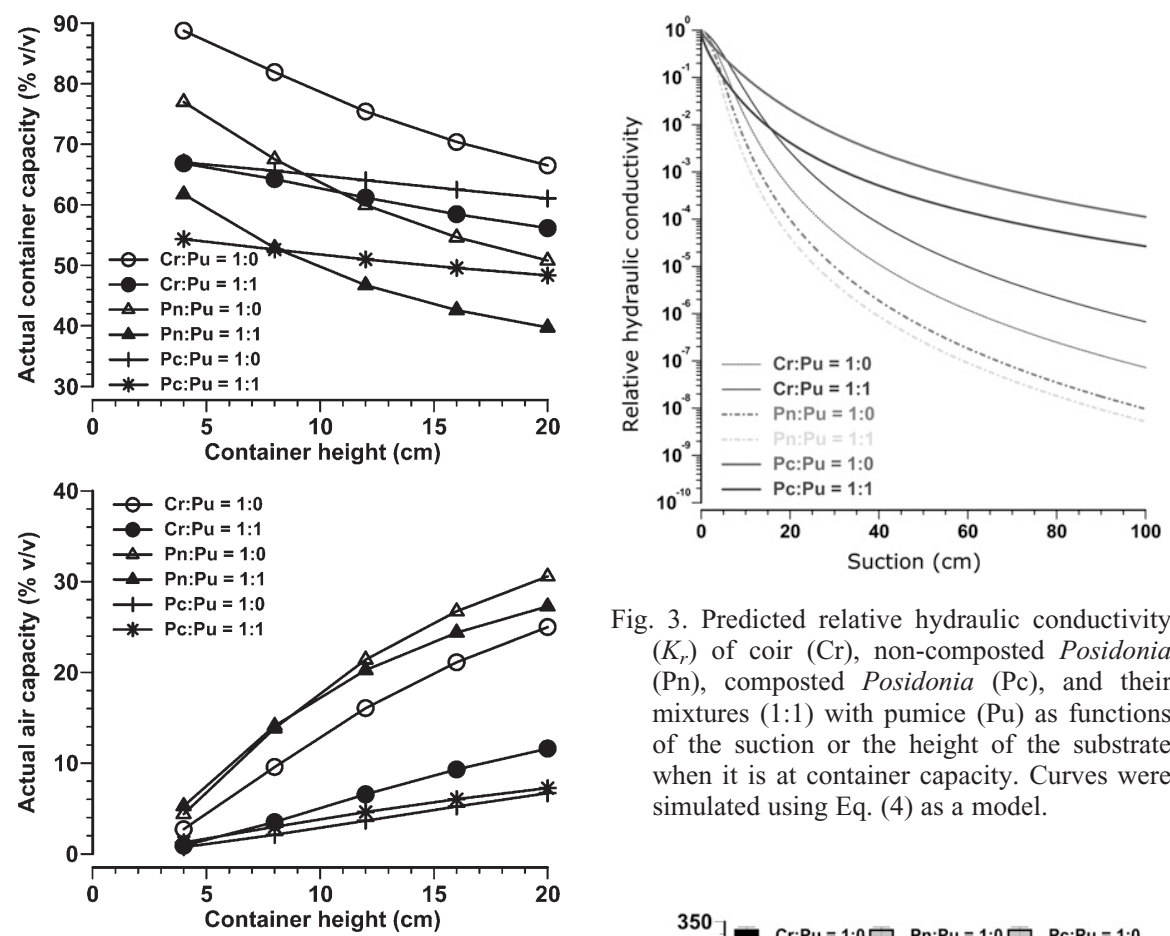

Fig. 2. Estimated actual container capacity and actual air capacity of containerized coir $(\mathrm{Cr})$, non-composted Posidonia (Pn), composted Posidonia $(\mathrm{Pc})$, and their mixtures (1:1) with pumice $(\mathrm{Pu})$ as influenced by the height of the substrate in the container. Estimations were based on the water retention curve (WRC) equations, which were simulated using four measurements at each suction level.

comparison with those grown on the $1: 1$ blends of coir or composted Posidonia with pumice. No significant difference in the mean fresh weight per lettuce plant could be found between the sole coir and the sole composted Posidonia treatments. However, the mean fresh weight per lettuce plant grown on both $100 \%$ non-composted Posidonia and its 1:1 blend with pumice was appreciably lower than that of plants grown on coir, composted Posidonia, and their 1:1 blends with pumice. Similar differences between treatments were obtained also when the dry shoot weight of lettuce was considered (data not shown).

The measurements of nutrient concentrations in the shoot of lettuce plants did not reveal any consistent difference among the
Fig. 3. Predicted relative hydraulic conductivity $\left(K_{r}\right)$ of coir $(\mathrm{Cr})$, non-composted Posidonia $(\mathrm{Pn})$, composted Posidonia $(\mathrm{Pc})$, and their mixtures (1:1) with pumice $(\mathrm{Pu})$ as functions of the suction or the height of the substrate when it is at container capacity. Curves were simulated using Eq. (4) as a model.

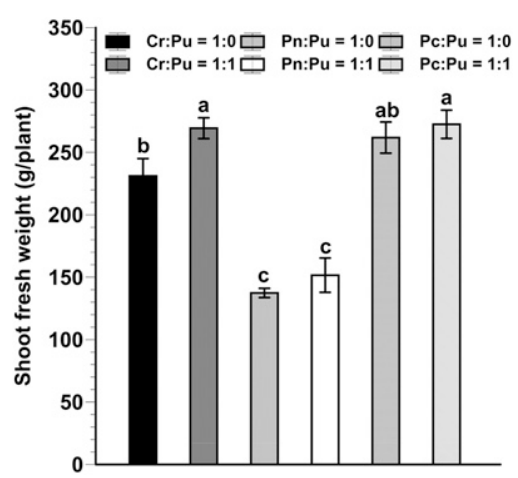

Fig. 4. Effect of the growing medium, specifically coir $(\mathrm{Cr})$, non-composted Posidonia (Pn), composted Posidonia $(\mathrm{Pc})$, and their mixtures $(1: 1)$ with pumice $(\mathrm{Pu})$, on the fresh weight of commercially ripe lettuce shoot. Values are means of four measurements. Vertical bars indicate \pm SEMS.

six substrates tested in this research (data not shown).

\section{Discussion}

Previous research has indicated that the non-linear function proposed by Van 
Genuchten (1980) for mineral soils (Eq. 3) provides adequate and accurate simulation of the relationship between moisture tension and volumetric water content for several growing media used in horticulture (Al Naddaf et al., 2011; Da Silva et al., 1993; Gizas and Savvas, 2007; Milks et al., 1989; Raviv et al., 1999), including coir (Raviv et al., 2001). The present research proved the adequacy of Eq. (3) to describe relevant experimental data also for non-composted and composted Posidonia residues, both unmixed and mixed with pumice, as well as for the 1:1 blend of coir with pumice. The WRC of coir that was estimated in the present study is very similar with that obtained by Raviv et al. (2001), although the model parameters $\theta_{s}, \theta_{r}, \mathrm{n}$, and $a$ are not identical $(0.92,0.40,2.40$, and 0.163 vs. 0.95 , $0.38,2.67$, and 0.087 , respectively). However, slight differences in hydraulic properties between samples of coir supplied from different commercial producers at different times are reasonable.

The effective pore space (which is equal to $\theta_{s}$ percent) of coir, composted, and noncomposted Posidonia proved to be higher than the corresponding values of their mixes with pumice. This finding is reasonable, because several researchers (e.g., Bilderback et al., 2005; Jones and Or, 1998) have shown that the water retention characteristics of media mixes are a compromise of the corresponding characteristics of the mix components. Indeed, as reported by Gizas and Savvas (2007), the $\theta_{s}$ of 0 to $8 \mathrm{~mm}$ pumice is 0.53 , which is much lower than those estimated in the present study for coir, composted, and non-composted Posidonia. Considering the same finding from another perspective, one can state that the EPS of pumice increases when it is mixed with coir or Posidonia, the latter being either in noncomposted or in composted condition. Similarly with the $\theta_{s}$, the $\mathrm{BD}$ values of the mixes were in between that reported by Gizas and Savvas (2007) for pumice (0.829) and the values of the corresponding mix components measured in the present study. Values falling in between of the ones reported by Gizas and Savvas (2007) for 0 to $8 \mathrm{~mm}$ pumice and those determined in this study for coir, noncomposted, and composted Posidonia were found also for WC and EAW in the corresponding mixes. However, the figures of $\theta_{s}$, $\mathrm{BD}, \mathrm{WC}$, and EAW in the $1: 1$ media mixes tested in the present study were not mean values of those found for the corresponding blend components. As reported by several investigators, when two media differing in particle size distribution are mixed, the final volume of the blend is less than the sum of the volumes of the individual components (e.g., Bilderback et al., 2005; Burés and Pokorny, 1991; Nash and Pokorny, 1990). The reduction in the volume of the blend, with reference to the sum of the volumes of the media components, occurs because small particles of the finer component occupy large pores of the coarser component (Spomer, 1974). Consequently, the mean size of the pores in the mix and concomitantly also its BD and EPS are not mean values of those of the two mix components.

Container capacity is a concept introduced by White and Mastalerz (1966) to describe the volumetric water content of a containerized substrate after saturation and subsequent completion of free draining. In the relevant scientific literature, the WC of a substrate, which is by definition (EN 13041, 1999) equal to the water content at a water suction of $1 \mathrm{kPa}$, is conventionally considered equal to the water content at container capacity (Brückner, 1997; Raviv et al., 2002). However, the actual water content at container capacity depends not only on the nature of the medium as is the case with the content of water held at $1 \mathrm{kPa}$, but also on container geometry (Al Naddaf et al., 2011; Bilderback and Fonteno, 1987; Klute, 1986). When comparing the actual water content at CC (Fig. 2) with the WC (Table 2), it becomes evident that for all substrates, the AWC is higher than the WC within the tested media height in the container and the two values become identical at media heights that exceed $20 \mathrm{~cm}$. Similarly to the WC, the conventionally defined air capacity (AC in Table 2) is lower than the actual air capacity (Fig. 2) when the height of the substrate layer in the container is lower than $20 \mathrm{~cm}$. However, most horticultural substrates are placed at lower layers than $20 \mathrm{~cm}$ in their receptors (commonly bags, pots, or troughs) when used for soilless cultivation of productive plants in greenhouses. Hence, the conventionally defined $\mathrm{WC}$ and $\mathrm{AC}$ do not provide a reliable estimation of the actual water and actual air content at CC in containerized substrates used for soilless culture.

The lowest values for both air capacity (Table 2) and actual air capacity (Fig. 2) were estimated in composted Posidonia irrespective of being unmixed or mixed with pumice, whereas the highest values were found for non-composted Posidonia and its mix with pumice. Furthermore, both the AC and the AAC were much higher in $100 \%$ coir than in its blend with pumice. However, the highest yield of lettuce was obtained from plants grown on composted Posidonia, both unmixed and mixed with pumice, as well as on the blend of coir with pumice. These results clearly show that the plant growth and yield was not restricted by air availability. When considering the WC, no clear relationship can be established between this substrate characteristic and the yield performance of lettuce. This finding is reasonable, because the WC includes both the plant-available and the unavailable water (Fonteno, 1989; Wallach, 2008) and, therefore, it is not a reliable criterion for the availability of water to the plants. The concept of the EAW that was introduced by De Boodt and Verdonck (1972) has long been used to assess the water availability to the plants. However, when this substrate characteristic is considered, in the present study, it is not possible to ascribe the differences in lettuce plant growth to the water availability. Indeed, the EAW was similar in non-composted and composted Posidonia, whereas the mean fresh weight of plants grown on non-composted Posidonia was much lower than that of plants grown on composted Posidonia. Furthermore, the mean fresh weight of plants grown on $100 \%$ coir was significantly lower than that of plants grown on its 1:1 mix with pumice, whereas the EAW was significantly higher in the former. The differences in mean fresh weight per plant could not be ascribed to dissimilarities in chemical properties between the tested substrates, because the nutrient concentrations in the shoot were similar in all treatments.

As pointed out by several researchers (Da Silva et al., 1993; Raviv et al., 2002; Wallach, 2008 ), the EAW is a static approach of water availability that ignores the resistance caused by the porosity in the water flux from the bulk of the substrate toward the surface of the root hairs. The latter is a crucial factor for water availability given that the plant water uptake results in depletion of water around the rhizosphere if the water flux in the porous media cannot keep pace with the rates of transpiration (Raviv et al., 2004). The water flux in porous media depends on the unsaturated hydraulic conductivity $(K)$. However, $K$ depends on the actual suction and thus also on the actual water content, which is a variable in between irrigation events (Wallach, 2008). Thus, the changes in the relative hydraulic conductivity as $\theta$ decreases and thus $\psi$ increases inside the substrate (Fig. 3) may provide a dynamic estimation of the water availability, which might be more reliable than that provided by the static approach of the EAW. Indeed, the differences in the rate of $K_{r}$ decrease with increasing $\psi$ between the tested substrates are largely similar with the differences in fresh weight of lettuce plants grown on them. In particular, the strongest decreases in $K_{r}$ with decreasing $\theta$ were observed in non-composted Posidonia, both unmixed and mixed with pumice, which rendered the lowest mean fresh weight per plant. On the other hand, the highest lettuce yield was obtained from composted Posidonia, which exhibited the lowest rate of $K_{r}$ decrease with increasing $\psi$. Furthermore, the significantly higher mean fresh weight of plants grown on the $1: 1 \mathrm{mix}$ of coir and pumice than on $100 \%$ coir seems reasonable if the rate of $K_{r}$ decrease with increasing $\psi$ is taken as a major criterion for water availability. Indeed, the rate of $K_{r}$ decrease with increasing $\psi$ was smaller in the former than in the latter. Nevertheless, the yield difference between plants grown on the 1:1 mix of coir and pumice and composted Posidonia, both unmixed and mixed with pumice, was insignificant, whereas a large difference in the rate of $K_{r}$ reduction was observed between them. However, the water flux depends ultimately on the unsaturated $K$, which is the product of $K_{r}$ and $K_{s}$. Hence, the higher $K_{r}$ values in the $1: 1 \mathrm{mix}$ of coir and pumice than in composted Posidonia may be offset by lower $K_{s}$ values that result in similar $K$ values within the critical range of $\psi$. Thus, estimation of $K_{s}$, which enables calculation of $K$ as a function of $\psi$ (Da Silva et al., 1993; Wallach, 2008; Wallach et al., 1992a), might provide a more reliable estimation of the changes in 
water fluxes as the suction or the height of the substrate in the containers increases.

The frequency of irrigation may strongly influence crop performance in soilless culture (Savvas et al., 2007; Silber et al., 2005). As pointed out by Lieth and Oki (2008), drainage fractions ranging up to $20 \%$ are commonly applied in substrate-grown crops, whereas Sonneveld and Voogt (2009) suggests drainage fractions up to $30 \%$. In the present study, the frequency of irrigation was adjusted to levels resulting in drainage fractions ranging between $20 \%$ and $30 \%$. Thus, our results are valid for well-irrigated crops. Under conditions of deficit irrigation (Fereres and Soriano, 2007), the differences in crop performance between the tested substrates might be even stronger, because in the present study, the observed differences were ascribed to limitations in water availability. On the other hand, higher leaching fractions might eliminate the differences in crop performance between media because they would maintain the water content at higher levels, thereby reducing the differences in hydraulic conductivity (Phene and Beale, 1976). Very high irrigation frequencies might even reverse the crop performance of the media as a result of restrictions in the air availability. Thus, the validity of the results obtained from the present research regarding the crop performance of the tested growing media is restricted to crops treated with similar irrigation practices.

\section{Literature Cited}

Al Naddaf, O., I. Livieratos, A. Stamatakis, I. Tsirogiannis, G. Gizas, and D. Savvas. 2011. Hydraulic characteristics of composted pig manure, perlite, and mixtures of them, and their impact on cucumber grown on bags. Sci. Hort. 129:135-141.

Bilderback, T.E. and W.C. Fonteno. 1987. Effects of container geometry and media physical properties on air and water volumes in containers. J. Environ. Hort. 5:180-182.

Bilderback, T.E., S.L. Warren, J.S. Owen, Jr., and J.P. Albano. 2005. Healthy substrates need physicals too. HortTechnology 5:747-751.

Bougoul, S., S. Ruy, F. de Groot, and T. Boulard. 2005. Hydraulic and physical properties of stonewool substrates in horticulture. Sci. Hort. 104:391-405.

Brückner, U. 1997. Physical properties of different potting media and substrate mixtures-Especially air- and water capacity. Acta Hort. 450:263-270.

Bunt, A.C. 1988. Media and mixes for containergrown plants. Unwin Hyman, London, UK

Burés, S. and F.A. Pokorny. 1991. Equation for estimating shrinkage in binary mixtures of container media. HortScience 26:1087.

Burés, S., F.A. Pokorny, D.P Landau, and A.M Ferrenberg. 1993. Computer-simulation of volume shrinkage after mixing container media components. J. Amer. Soc. Hort. Sci. 118:757-761.

Castaldi, P. and P. Melis. 2004. Growth and yield characteristics and heavy metal content on tomatoes grown in different growing media. Commun. Soil Sci. Plant Anal. 35:85-98.

Cocozza, C., A. Parente, C. Zaccone, C. Mininni, P. Santamaria, and T. Miano. 2011. Chemical, physical and spectroscopic characterization of Posidonia oceanica (L.) Del. residues and their possible recycle. Waste Mgt. 31:78-84.

Da Silva, F.F., R. Wallach, and Y. Chen. 1993. Hydraulic properties of sphagnum peat moss and tuff (scoria) and their potential effects on water availability. Plant Soil 154:119-126.

De Boodt, M. and O. Verdonck. 1972. The physical properties of the substrates in horticulture. Acta Hort. 26:37-44.

EN 13041. 1999. Soil improvers and growing media-Determination of physical propertiesDry bulk density, air volume, water volume, shrinkage value and total pore space. CE de Normalisation, Brussels, Belgium.

Evans, M.R., S. Konduru, and R.H. Stamps. 1996. Source variation in physical and chemical properties of coconut coir dust. HortScience 31:965-967.

Fereres, E. and M.A. Soriano. 2007. Deficit irrigation for reducing agricultural water use. J. Expt. Bot. $58: 147-159$.

Fonteno, W.C. 1989. An approach to modelling air and water status of horticultural substrates. Acta Hort. 238:67-74.

Gizas, G. and D. Savvas. 2007. Particle size and hydraulic properties of pumice affect growth and yield of greenhouse crops in soilless culture. HortScience 42:1274-1280.

Heiskanen, J. 1995. Physical properties of twocomponent growth media based on sphagnum peat and their implications for plant-available water and aeration. Plant Soil 172:45-54.

Jones, S.N. and B. Or. 1998. Design of porous media for optimal gas and liquid fluxes to plant roots. Soil Sci. Soc. Amer. J. 62:563-573.

Klute, A.(ed.). 1986. Water retention: Laboratory methods, p. 635-660. In: Methods of soil analysis. Part I, physical and mineralogical methods. 2nd Ed. Monograph 9. Am. Soc. Agron., Madison, WI.

Lieth, J.H. and L.R. Oki. 2008. Irrigation in soilless production, p. 117-156. In: Raviv, M. and H.J. Lieth (eds.). Soilless culture: Theory and practice. Elsevier, Amsterdam, The Netherlands.

Londra, P.A. 2010. Simultaneous determination of water retention curve and unsaturated hydraulic conductivity of substrates using a steady-state laboratory method. HortScience 45:1106-1112.

Maher, M.J., M. Prasad, and M. Raviv. 2008 Organic soilless media components, p. 459504. In: Raviv, M. and H.J. Lieth (eds.). Soilless culture: Theory and practice. Elsevier, Amsterdam, The Netherlands.

Milks, R.R., W.C. Fonteno, and R. Larson. 1989. Hydrology of horticultural substrates: I. Mathematical models for moisture characteristics of horticultural container media. J. Amer. Soc. Hort. Sci. 144:48-52.

Mualem, Y. 1976. A new model predicting the hydraulic conductivity of unsaturated porous media. Water Resour. Res. 12:513-522.

Nash, M.A. and F.A. Pokorny. 1990. Shrinkage of selected two-component container media. Hort. Sci. 25:930-931.

Nektarios, P.A., N. Ntoulas, S. McElroy, M. Volterrani, and G. Arbis. 2011. Effect of olive mill compost on native soil characteristics and tall fescue turfgrass development. Agron. J. 103:1524-1531.

Papadopoulos, A.P., A. Bar-Tal, A. Silber, U.K. Saha, and M. Raviv. 2008. Inorganic and synthetic organic components of soilless culture and potting mixes, p. 505-543. In: Raviv, M. and H.J. Lieth (eds.). Soilless culture: Theory and practice. Elsevier, Amsterdam, The Netherlands.

Phene, C.J. and O.W. Beale. 1976. High-frequency irrigation for water nutrient management in humid regions. Soil Sci. Soc. Amer. J. 40:430-436.

Raviv, M., J.H. Lieth, D.W. Burger, and R. Wallach. 2001. Optimization of transpiration and potential growth rates of 'Kardinal' rose with respect to root-zone physical properties. J. Amer. Soc. Hort. Sci. 126:638-643.
Raviv, M., R. Wallach, and T.J. Blom. 2004. The effect of physical properties of soilless media on plant performance-A review. Acta Hort. 644:251-259.

Raviv, M., R. Wallach, A. Silber, and A. Bar-Tal. 2002. Substrates and their analysis, p. 25-101. In: Savvas, D. and H.C. Passam (eds.). Hydroponic production of vegetables and ornamentals. Embryo Publications, Athens, Greece.

Raviv, M., R. Wallach, A. Silber, Sh. Medina, and A. Krasnovsky. 1999. The effect of hydraulic characteristics of volcanic materials on yield of roses grown in soilless culture. J. Amer. Soc. Hort. Sci. 124:205-209.

Savvas, D. 2003. Hydroponics: A modern technology supporting the application of integrated crop management in greenhouse. J. Food Agr. Environ. 1:80-86.

Savvas, D. 2009. Modern developments in the use of inorganic media in greenhouse vegetable and flower production. Acta Hort. 819:73-86.

Savvas, D., E. Nasi, E. Moustaka, N. Mantzos, P. Barouchas, H.C. Passam, and C. Olympios. 2006. Effects of ammonium nitrogen on lettuce grown on pumice in a closed hydroponic system. HortScience 41:1667-1673.

Savvas, D., E. Stamati, I.L. Tsirogiannis, N. Mantzos, P.E. Barouchas, K. Kittas, and N. Katsoulas. 2007. Interactions between salinity and irrigation frequency in greenhouse pepper grown in a closed-loop hydroponic system. Agr. Water Mgt. 91:102-111.

Serio, F., L. de Gara, S. Caretto, L. Leo, and P. Santamaria. 2004. Influence of an increased $\mathrm{NaCl}$ concentration on yield and quality of cherry tomato grown in posidonia [Posidonia oceanica (L) Delile]. J. Sci. Food Agr. 84:1885-1890.

Silber, A., M. Bruner, E. Kenig, G. Reshef, H. Zohar, I. Posalski, H. Yehezkel, D. Shmuel, S. Cohen, M. Dinar, E. Matan, I. Dinkin, Y. Cohen, L. Karni, B. Aloni, and S. Assouline. 2005. High fertigation frequency and phosphorus level: Effects on summer-grown bell pepper growth and blossom-end rot incidence. Plant Soil 270:135-146.

Sonneveld, C. and N. Straver. 1994. Nutrient solutions for vegetables and flowers grown in water or substrates. 10th Ed. Serie: Voedingsoplossingen Glastuinbouw, No. 8. P.B.G. NaaldwijkP.B.G. Aalsmeer, The Netherlands.

Sonneveld, C. and W. Voogt. 2009. Plant nutrition of greenhouse crops. Springer, Dordrecht, The Netherlands; Heidelberg, Germany; London, UK; New York, NY.

Spomer, L.A. 1974. Optimizing container soil amendment: The threshold proportion and prediction of porosity. HortScience 9:532-533.

Van Genuchten, M.T.H. 1980. A closed-form equation for predicting the hydraulic conductivity of unsatured soils. Soil Sci. Soc. Amer. J. 44:892-898.

Van Genuchten, M.Th. and D.R. Nielsen. 1985. On describing and predicting the hydraulic properties of unsaturated soils. Ann. Geophys. 3:615-628.

Wallach, R. 2008. Physical characteristics of soilless media, p. 41-116. In: Raviv, M. and H.J. Lieth (eds.). Soilless culture: Theory and practice. Elsevier, Amsterdam, The Netherlands.

Wallach, R., F.F. da Silva, and Y. Chen. 1992a. Hydraulic characteristics of tuff (Scoria) used as a container medium. J. Amer. Soc. Hort. Sci. 117:415-422.

Wallach, R., F.F. da Silva, and Y. Chen. 1992b. Hydraulic characteristics of tuff (scoria) used as a container medium. J. Amer. Soc. Hort. Sci. 117:415-422.

White, J.W. and J.W. Mastalerz. 1966. Soil moisture as related to container capacity. Proc. Amer. Soc. Hort. Sci. 89:757-765. 